\title{
Developing an Electronic Device to Teach English as a Foreign Language: Educational Toy for Pre-Kindergarten Children
}

\author{
https://doi.org/10.3991/ijet.v14i22.11747 \\ Abdo Sulaiman Abdi $(\bowtie)$ \\ Duhok Polytechnic University, Duhok Iraq \\ abdo.abdi@dpu.edu.krd \\ Nadire Cavus \\ Near East University, Nicosia Cyprus
}

\begin{abstract}
These Educational toys are important in early child development and motivate children to learn language. Numerous digital toys are now available in the children's educational toys market to help children learn foreign languages. However, a number of such technologies are expensive and the quality of usability is not at an acceptable level. The aim of the study is to develop a cost-effective, sustainable and danger-free educational toy for pre-kindergarten children aged between 4-5 years old to teach English as a second language in developing countries. This toy has been developed with Raspberry Pi and makes use of the RFID technology. The experiment in this research was conducted with 20 pre-kindergarten children for four weeks under the supervision of 14 teachers, using five games of the developed toy testing the prekindergarten children's learning of alphabet, words, colors, shapes, and numbers. A design-based research model with an innovation design method utilized during the development stage of the toy. Quantitative and qualitative methods were used to evaluate the developed toy. The results of the experiment showed that the developed toy is user-friendly, and the pre-kindergarten children were enthusiastic about playing with it and learning was enjoyable. Also, the results showed that the developed toy can be suitable for use as an educational toy for pre-kindergarten children to teach English as a second language. The educational toy developed by the researchers will be beneficial for those who wish to teach English to pre-kindergarten children such as administrators, teachers and parents in developing countries.
\end{abstract}

Keywords-Educational toys, English teaching, pre-kindergarten children, smart cards, Raspberry Pi, Radio Frequency Identification, RFID

\section{Introduction}

English is considered to be the most popular language spoken around the world [1; 2], which means it is highly necessary for non-English speaking countries [3] to adopt 
English as a second means of communication [4]. It is known that pre-kindergarten level is the most important period of change in children's physiology and psychology during early childhood $[5 ; 6]$. At the same time, pre-kindergarten is the initial stage in which foreign language learning is more effective and easier than at ater age $[7 ; 8$; 9]. Also, it is well-known that most parents start encouraging their children to learn English as a second language in non-English speaking countries when they are less than six years old.

There are numerous types of digital technologies available to help children learn foreign languages [10], such as personal computers, laptops, mobile devices, etc. [11]. However, many researchers $[12 ; 13]$ have underlined that exposing children to the use of mobile devices and other electronic devices specifically with Internet connectivity has a negative impact on them [14]. Due to the internet connectivity of these devices, children can also access unwanted content that may have negative effects. Moreover, it has been found that these devices bring numerous health challenges such as eye problems [12], harmful effects on the brain [13], cancer [15] and non-malignant tumors [16]. Frequently using these devices can also negatively affect children's social lives and behavior [17]. Another problem is that of erratic Internet access [18] and expensive educational technologies [19] in developing non-English speaking countries. Conversely, integrating digital toys into learning environments provides benefits for children in pre-kindergarten [20]. It enhances the educational value of children's play [21] and enables physical objects to be effectively connected to virtual content of the learning material [22]. However, a number of such technologies are expensive and the quality of usability is not at an acceptable level [23]. Although the children's educational toys market is rapidly developing, the existing children's toys cannot meet the needs of children and do not have innovative features [5].

\subsection{The aim}

The main aim of the study is to develop an educational toy that will help prekindergarten children to learn English language as a second language. To achieve this, the toy evaluated to determine whether it assists pre-kindergarten children from nonEnglish speaking countries. The authors searched for answers to the following questions to identify whether the developed toy can be used for educational purposes:

- What is the success of the pre-kindergarten children?

- What are teachers' opinions about the developed toy?

- What are the pre-kindergarten children's opinions regarding the developed toy?

\section{$2 \quad$ Related Research}

As a result of the development of technology, it is understood from research conducted in recent years that the use of educational toys by pre-kindergarten children generates positive results $[24 ; 25 ; 26]$.

Kubicki et al. [27] designed and developed an interactive Tabletop RFID device, also known as TangiSense, for children from aged from 3 to 5 years old. The test 
results of their study showed that children learnt numbers, alphabet, and words. Consequently, they suggested that the developed device can be used for to strengthen teaching in cases that are difficult or problematic with traditional techniques. Another interactive educational toy was developed by Yilmaz [28] for children aged 5-6. The aim of their study was to teach animals, vegetables, fruits, automobiles, items, shapes, colors, and numbers using animation flash cards. Quantitative and qualitative results indicated that teachers and children who participated their study were interested in the developed toy. On the other hand, Jeong et al. [26] developed a talking doll toy named I-Eng, for children between 3 and 5 years old. It was used to teach a second language to children with the "learning by doing" method. Also, the results of Güngör's [29] study found that English-speaking toys can be used to teach vocabulary in the English language in particular. Kekuluthotuwage and Fernando [24] stressed that a voicebased learning strategy together with the "learning by doing" method should be used when attempting to teach a second language to children.

\section{Theoretical Framework}

\subsection{Importance of learning English languages}

While globalization increases, English and consequently the interest in learning English have become more important in human life [30; 31]. People need to know English to communicate with other people around the world [3; 32]. Also, one of the factors necessary to obtain a good job in any sector is the ability to speak English [33]. All of these necessities have made English the global language [34; 35]. The best period for learning English as a foreign language is childhood [8], and prekindergarten teachers believe that it is easy to teach children in this age bracket [9]. Today's children born in the digitalizing world are considered the $\mathrm{Z}$ generation and they expect new and challenging forms of learning in their class.

\subsection{Educational toys for children}

Educational toys help children to develop a certain skill or provide a specific topic on a particular subject. The most important features of educational toys are strong intelligence and entertainment [5]. Educational toys are important in early child development in facilitating language interactions as well as increasing the ability to interact socially with friends [19]. Also, educational toys have a significant impact on re-designing children's experiences, improving their imagination, changing their behaviors $[28 ; 36]$, supporting children's play, and promoting the development of their intelligence [5].

Children enjoy to play and spend more time playing with toys [37]. On the other hand, Srivastava and Noval [38] highlighted that playing games on digital toys makes language learning more engaging, productive and relevant for kindergarten. Therefore, playing is an essentially part of children's developmental activities [39]. Furthermore, the enrichment of children especially in pre-kindergarten necessitates playing [40]. As indicated by modern kindergarten educational programs, gameplay is a 
significant reason for children's advancement and it is the primary impetus when structuring instructive exercises [41].

Educational toys motivate children [42] to learn foreign languages in or out of the classroom, particularly English. Kenny and McDaniel [43] highlighted that educational play is impactful on children. For this reason, Yilmaz [28] argued that educational toys are valued as important tools for children's learning in the literature.

\section{$4 \quad$ Methodology}

A design-based research model with an innovation design method was adopted during the development stage of the toy. Correspondingly, the toy was developed based on the design specifications for educational toys for pre-kindergarten children. Also, Creswell and Clark [44] highlighted that the data collected by mixed methods are effective in achieving more accurate results in any scientific study. Therefore, quantitative and qualitative analysis techniques were used together in this study.

\subsection{Participants}

The random sampling technique was used during the selection of participants and the experimental study was conducted in a pre-kindergarten class in Irak-KRGDuhok-Sharya. Fraenkel and Wallen [45] underlined that 10-20 participants can be accepted for expe rimental studies, but the researcher should focus on each participant individually. Therefore, in this study, the researchers of the study maintained close relationships with the children and teachers in all stages of the study. The framework of the study is presented in Table 1.

- Children: 20 randomly selected pre-kindergarten children in the 4-5-year-old age group were included this study. Before the experimental study, permission was obtained from the children's parents for participation the study.

- Teachers: 14 voluntary pre-kindergarten teachers participated to the study. All of them were female because of the education policy for pre-kindergartens in Iraq. The average age of teachers was 30 years old.

Table 1. Framework of this study

\begin{tabular}{|l|l|l|}
\hline & \multicolumn{1}{|c|}{ Children } & \multicolumn{1}{c|}{ Teacher } \\
\hline Participant & $\begin{array}{l}\text { 20 pre-kindergarten children } \\
4-5 \text { years old } \\
\text { 8 girls + 12 boys } \\
\text { Average age 4.6 years old }\end{array}$ & $\begin{array}{l}14 \text { teachers } \\
25-40 \text { years old } \\
\text { All of them female } \\
\text { Average age is 30 }\end{array}$ \\
\hline Learning Strategy & Group-based learning & \\
\hline Duration & 4 weeks & 4 weeks \\
\hline Evaluation of the study & $\begin{array}{l}\text { Semi-structured interview } \\
\text { Academic performance test }\end{array}$ & Survey method (Questionnaire) \\
\hline
\end{tabular}




\subsection{Data collection tools}

The design of any system or application targeted at pre-kindergarten children is complicated. Therefore, information was gathered from teachers and children [46]. Also, the developed system was tested to decide whether it is suitable for children and the purpose of the study.

The survey method was conducted to obtain quantitative data in order to determine the opinions of the teachers related to the functional and non-functional features of the developed toy. Also, to determine whether the developed toy is suitable for children to use as an educational toy for learning the English language. The questionnaire was adapted from Cavus and Ibrahim [47]. Furthermore, the validity of the questionnaire items was checked by educational technologies experts, English language teachers, and measurement and assessment experts. On the other hand, the Cronbach's alpha was used to assess the internal consistency of the questionnaire, and it was calculated as .89. It can be said that the survey will be reliable because the calculated Cronbach alpha's coefficient is greater than .70 [48]. The questionnaire consisted o 13 items formed of a 5-point Likert scale type where the "Strongly Agree" response scored 5 and "Strongly Disagree" response scored 1.

On the other hand, a "Learning success test" was administered to the children to determine the learning capabilities of the developed toy in terms of letters, numbers, words, colors, and shapes in the English language. The results were obtained after the experiment via playing with the developed toy.

Children were carefully observed when playing with the toy by researcher and teachers. Then, semi-structured interviews were conducted to obtain qualitative data from the children after they had played with the developed toy for four weeks. Since the participants of the study were pre-kindergarten children, it was important to take their psychology into account. For this reason, a familiar class teacher was also present in the interview room together with the researchers during the interviews. Only three main easily understandable questions were asked in order to obtain their opinions on the developed toy. As a result, they would not become bored because each interview only lasted 5 minutes. The children's answers were noted by the researchers.

\subsection{Data analysis methods}

Descriptive statistics of mean, frequency percentage and standard deviation were used to analyze the collected data of the study.

\subsection{The developed educational toy}

Python (ver 2.7.9) programming language was used to develop this toy. The main technological parts of the developed toy are 2 speakers, MFRC-522 RC522 RFID Radio frequency reader and 72 smart cards (26 English alphabet, 10 numbers, 5 main colors, 5 shapes, and 26 simple English words) with a high frequency of $13.56 \mathrm{MHZ}$. "Sunrise-1 Student Book" [49] was used as a guide/resource for all tags mean images 
that were printed on the smart cards. Figure 1 shows the structure of the developed toy.

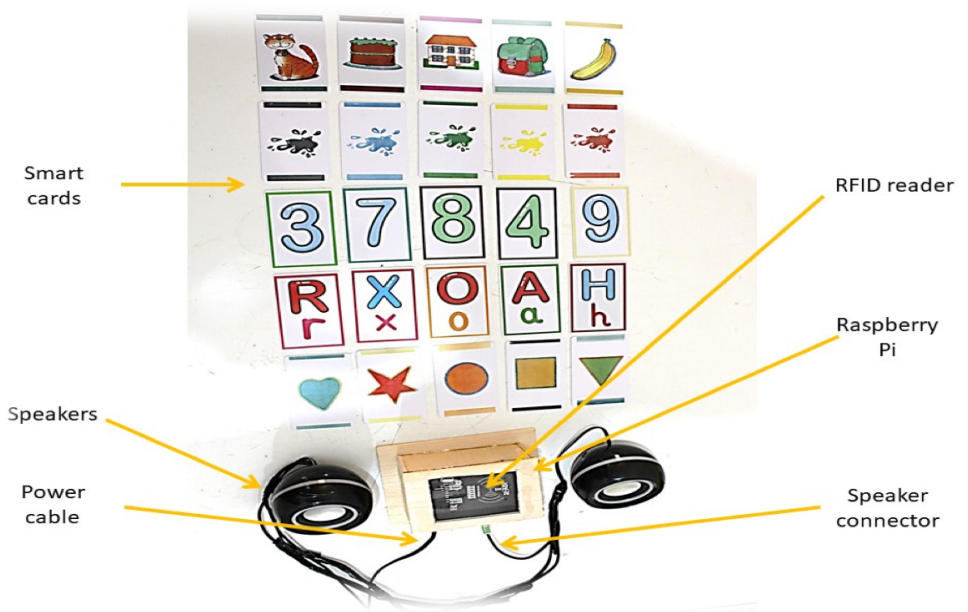

Fig. 1. The structure of the developed educational toy

The developed toy consists of 5 different games. The first game is related with 26 English letters, the second game is related with 10 numbers between 0 to 9 , the third one is related with 26 simple English words, the fourth one is related with 5 main colors and the last game related with the 5 most well-known shapes. Figure 2 shows the smart cards used in the study.

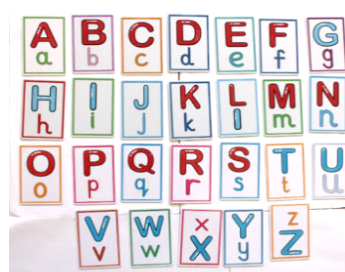

(a) Alphabet

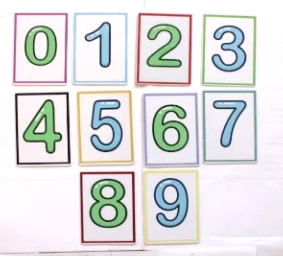

(b) Numbers

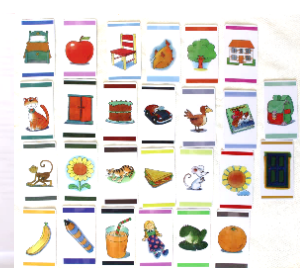

(c) Words

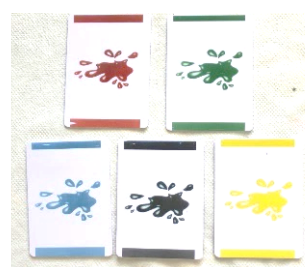

(d) Colours

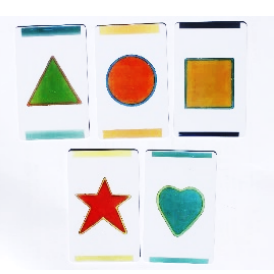

(e) Shapes

Fig. 2. Smart cards' tags of all games on the developed toy 
The playing logic of the developed game is as follows: Based on the selected game, the toy choses randomly chooses any letter, number, word, color or shape from the list and announces them to the children. The children listen carefully and select the related smart card and place it on the toy's reader. When the right answer is given by the child, the toy automatically says voice messages such as "Perfect", "Good", "Amazing", etc. to motivate them and make the game interesting. Kekuluthotuwage and Fernando [24] suggested that voice is a valuable trait in designing interactive gamification technology for children. In case of wrong answers, the toy gives different voice messages such as "Try again", "Be careful", "Try again", "Next time you can succeed" etc. to the children. This audio feedback motivates the children to continue playing games. They need only request to play with this developed toy. It can be said that the innovation design method [50] is useful for this type of scientific research because a specific goal, timely and accurate feedback, the unity of behavior and consciousness, potential thinking guide were verified through a real case study. Consequently, the children were able to learn English while they were playing (Figure 3).
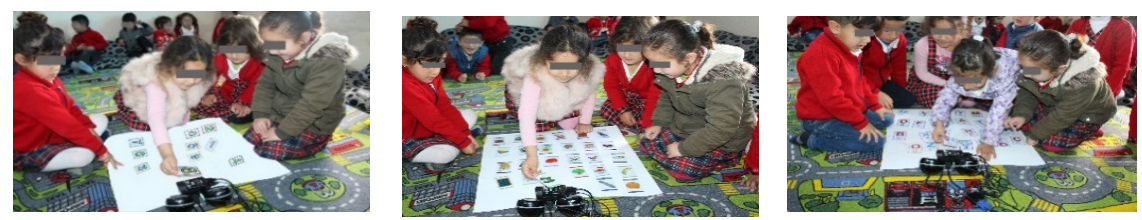

Fig. 3. Some snapshots from the experimental study

\section{Special features of the developed toy are as following:}

- Cost effective: The developed toy is cost effective because the main components used for the toy are cheap.

- User friendly: The developed toy is user friendly for pre-kindergarten children because the instructions are well structured by audio messages.

- Secure: The developed toy is secure because it has been properly covered to protect children from any electric shocks, and there is no Internet connection that parents of pre-kindergarten children should be concerned about. Also, it can be said that it does not have any side effects in terms of the children's mental health.

\subsection{Implementation}

Firstly, a game was designed for educational purposes including the contents of the Sunrise-1 Student Book, which is used as a resource book to teach English to prekindergarten children in Iraq. A random class was chosen from the Iraq-KRG-DuhokSharya pre-kindergarten. Twenty children were randomly selected after obtaining permissions from their parents. Fourteen teachers from the same school who were willing to participate voluntarily were also included in the study. At the beginning of the study, pre-prepared smart cards tags were shown to the children in order to determine what they did or did not know, and they were asked to say the name of the 
tags on these smart cards. The unknown tags were then marked on a pre-prepared list according to the answers given by the students. Thus, only the unknown letters, numbers, words, colors and shapes were included in the experimental study. Then, for four weeks, the children played the developed toy during the class hours in the presence of the classroom teacher, researchers, and other participating teachers. The children were divided into groups of 3-4 people. Every day, the group members changed. At the end of 4 weeks, this time the children's games were watched and the known words from the list (the ones that were answered correctly) were marked. One day after the evaluation, the children were interviewed and their opinions about the system were determined. At the same time, teachers used the developed toy to evaluate it in order to understand whether it could be used as an educational toy for pre-kindergarten children. In addition, teachers' opinions about the system were collected by a questionnaire. The study was completed by analyzing the results with the appropriate statistical methods (Figure 4).

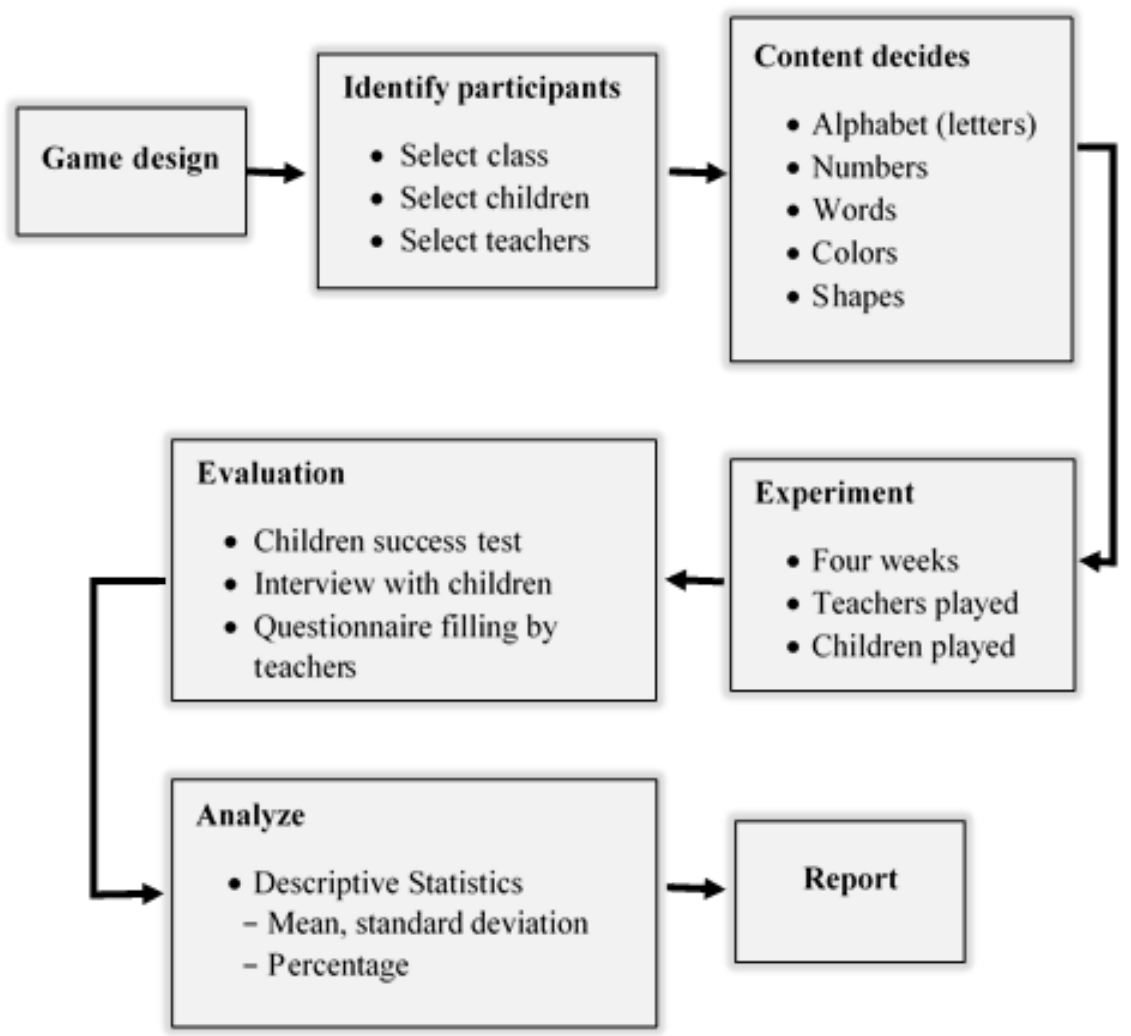

Fig. 4. The implementation of the study 


\section{$5 \quad$ Results}

\subsection{Success of pre-kindergarten children}

Since the developed educational toy consisted of five different games, the success of the students was determined by testing each game separately from the results are presented in Table 2 .

- Alphabet testing: At the beginning of the study, it was determined that the children did not know 11 (A-K) of the 26 English letters. Therefore, the 15 English letters that the children did not know were included in the experimental study. The children were examined again at the end of the study to determine how many of the English letters had been learned by using the developed toy. The result showed that 13 of the 15 English letters had been learned by the children. It was determined that only two letters, namely "Q" and "P", could not be learned.

- Number testing: It was identified at the beginning of the study that the children knew the numbers 1, 2, 3, 4 and 5 but they did not know the numbers $0,6,7,8$ and 9. At the end of the experimental study, the results indicated that all included numbers had been learned by the children after using the developed toy.

- Word testing: At the beginning of the study, it was determined that the children knew only 7 simple words, namely apple, cat, car, pizza, doll, sunflower, and door. Therefore, these words were eliminated from the experimental study. Nineteen simple words taken from the reference book were included in the study. Children were examined again at the end of the study to determine how many of the words had been learned by using the developed toy. The results revealed that 16 of the 19 words had been learned by the children. However, the children were unable to learn the words "Cupboard", "Tiger", and "Mouse" from the toy.

- Color testing: It was identified at the beginning of the study that the children knew only the color white. At the end of the experimental study, the results showed that that other included colors (Red, Green, Yellow, Black and Blue) had been learned by the children.

- Shape testing: At the beginning of the study, the shapes to be included in the study were determined. Initially, it was found that the children did not know the shapes square, star, triangle, heart, and circle. Subsequently, the children were able to confidently differentiate and learn all the shapes in the developed toy at the end of the fourth week.

Table 2. Results of the experimental study

\begin{tabular}{|l|c|c|}
\hline \multicolumn{1}{|c|}{ Game } & Learned & Total \\
\hline Letters & 13 & 15 \\
\hline Numbers & 5 & 5 \\
\hline Words & 16 & 19 \\
\hline Colors & 5 & 5 \\
\hline Shapes & 5 & 5 \\
\hline
\end{tabular}




\subsection{Opinions regarding the developed toy}

The descriptive statistics were used in order to obtain the teachers' and prekindergarten children's opinions regarding the developed toy.

Teachers' opinions towards the developed toy: It can be seen from Table 3 that in general, teachers' opinions were positive toward the developed toy. The mean for only two items was less than 4.0, although they were still considered acceptable. These results can be accepted as a good result in most researches. All other mean scores in the table were positive.

The highest mean of teachers' opinions was from item 10 "I would like to see the developed toy be used in the future $(M=4.93 ; S D=0.27)$ ". The teachers monitored the children's learning achievement at the end of the experimental study. It could be thought that it was effective in expressing positive opinions on this item. The second highest mean of the teachers' opinions was from item 7 "The developed toy helped children to correctly learn the meaning of the smart cards' tag $(M=4.93 ; S D=0.27)$ ". The importance of understanding the correct meaning of words is paramount in the early academic lives of children [51]. Based on this perception, it could be said that the developed toy might boost the teachers' opinions in regard to the increased quality of education. This could lead to the continuous use of the developed toy in their classes in the future. The third highest mean of teachers' opinions was found in relation to item 2 "I think all of my students who used the developed toy are happy about it $(M=4.86$; $S D=0.36)$ ". This could be indicator that the variety of functions offered by the toy do play an important role in making the developed toy a usable educational instrument that makes learning enjoyable.

The lowest mean was recorded for item 6 "With the help of the developed toy, I learned new techniques easily ( $M=3.79 ; S D=0.70)$ )". Children played with the developed toy on their own or with their classmates. The toy was easy to use and userfriendly, which meant that the children did not need their teacher's help. Teachers used the collaborative learning technique as they were already aware of this method. The second lowest mean was obtained for item 8 "The developed toy helped children learn the pronunciation of the smart cards' tag easily $(M=3.86$; $S D=3.86)$ ". This item involved inquiry about something related to the auditory opinions of the children. As such, the sound functionalities of the developed toy were not something that the children were acquainted with. Children were familiar with directly listening to human voices of their instructors or parents. For this reason, children could be affected by hearing the computerized sounds. This negative feeling of children might have a negative effect on the teachers' opinions. 
Table 3. Descriptive statistics of teachers' opinions

\begin{tabular}{|l|c|c|}
\hline Item & Mean & SD \\
\hline I found the developed toy system enjoyable. & 4.71 & 0.61 \\
\hline I think all of my students who used the developed toy are happy about it. & 4.86 & 0.36 \\
\hline $\begin{array}{l}\text { I think the students can easily remember the words/shapes/ colors/letters/numbers they } \\
\text { used on the developed toy. }\end{array}$ & 4.64 & 0.50 \\
\hline $\begin{array}{l}\text { The name of the smart card's tags children learned with the developed toy has increased } \\
\text { their vocabularies. }\end{array}$ & 4.00 & 0.55 \\
\hline I would like the developed toy to be used in other English classes. & 4.71 & 0.61 \\
\hline With the help of the developed toy, I learned new techniques easily. & 3.79 & 0.70 \\
\hline The developed toy helped children to correctly learn the meaning of the smart cards' tag. & 4.79 & 0.43 \\
\hline The developed toy helped children learn the pronunciation of the smart cards' tag easily. & 3.86 & 0.86 \\
\hline The developed toy has motivated children to learn. & 4.43 & 0.65 \\
\hline I would like to see the developed toy be used in the future. & 4.93 & 0.27 \\
\hline I found learning new words with the developed toy very effective. & 4.36 & 0.50 \\
\hline The colors used on the smart cards tag are suitable for children. & 4.43 & 0.51 \\
\hline $\begin{array}{l}\text { The sound effects that have been used in the developed toy add extra motivation for } \\
\text { children to learn. }\end{array}$ & 4.29 & 0.83 \\
\hline
\end{tabular}

*Scoring: "Strongly Agree" = 5 and "Strongly Disagree" = 1

Pre-kindergarten children's opinions toward the developed toy: After the children had played with the developed toy for four weeks, interviews were held with them separately to obtain their opinions toward the developed toy. Based on the interview findings, the highest percentage was obtained from question 3 , which related with enjoyment (92\%). Also, $90 \%$ of them said that wanted to play with the developed toy every day. It can be said that they liked the developed toy, as they were able to match their answers to the corresponding smart cards (correct answer). In addition, the children' opinions indicated that they were inclined to use the developed toy in the future. The lowest percentage obtained was related to sounds $(85 \%)$. The reason for this could be that the pre-kindergarten children prefer natural sounds rather than artificial sounds. Table 4 shows the children's opinions after playing with the developed toy for four weeks.

Table 4. Descriptive statistics of children' opinions

\begin{tabular}{|l|c|}
\hline Item & Percentage \\
\hline 1. Do you want to play with the developed toy every day? & $90 \%$ \\
\hline 2. Do you like the sounds used in the developed toy? & $85 \%$ \\
\hline 3. Do you enjoy playing with the developed toy? & $92 \%$ \\
\hline
\end{tabular}

\section{Conclusion and Future Work}

In this study, a cost-effective, sustainable and risk-free educational toy was developed for pre-kindergartens in developing countries such as Iraq to teach English as a second language. The results of the experiment revealed the potential of the developed toy for enhancing pre-kindergarten children's learning abilities in regard to letters, numbers, words, colors, and shapes, which are essential aspects of the English 
language. The study also fills the knowledge gap, as suggested by Kubicki et al. [27], that future educational toys should include numbers, letters and words, not only colors. Consequently, it can be said that the developed toy is suitable for use as an educational toy for pre-kindergarten children for teaching English as a second language. We hope that the implementation of the developed toy in pre-kindergarten will positively affect children's learning abilities and simplify the learning process. In addition, the educational toy developed by researchers will be beneficial for those who wish to teach English to pre-kindergarten children such as administrators, teachers and parents in developing countries.

\subsection{Suggestions for future work}

The system can be improved in future studies:

- Natural human voices, advanced functions of artificial voice, should be used in the system of the toy to improve the understanding of the pronounced words

- Other shapes, colors and words could be added to the toy

- The developed toy could be used in other pre-kindergarten classes

- The number of children could be increased to obtain more accurate results

- The developed educational toy could be tested with children in different prekindergartens

\section{$7 \quad$ Acknowledgement}

The authors acknowledge and thank all pre-kindergarten children and teachers who spent their valuable time by participating in this study and by helping to evaluate the results of the developed educational toy.

\section{Disclosure Statement}

No potential conflict of interest was reported by the authors.

\section{References}

[1] Guilherme, M. (2007). English as a global language and education for cosmopolitan citizenship. Language and Intercultural Communication, 1(7): 72-90. https://doi.org/10.2167/ $\underline{\text { laic } 184.0}$

[2] Gayton, A. M. (2016). Perceptions about the dominance of English as a global language: impact on foreign-language teachers' professional identity. Journal of Language, Identity \& Education, 15(4): 230-244. https://doi.org/10.1080/15348458.2016.1194209

[3] Hu, Z. (2013). Emerging vocabulary learning: from a perspective of activities facilitated by mobile devices. English Language Teaching, 6(5): 44-54. https://doi.org/10.5539/elt.v6n $\underline{5 p 44}$ 
[4] Dahiya, A. (2017). Challenges and benefits of learning English as a second language (ESL). International Journal of Engineering Technology Science and Research, 4(9): 11281131.

[5] Tengfei, W. (2016). Analysis on the design of children's puzzle toys. Advances in Social Science, Education and Humanities Research, 85: 302-206.

[6] Tarekegne, W., and Megersa, A. (2019). Preschool curriculum implementation in Ethiopia: The case of selected woredas preschools. Cypriot Journal of Educational Sciences, 14(2): 178-189. https://doi.org/10.18844/cjes.v14i2.3882.

[7] Haznedar, B. (2013). Child second language acquisition from a generative perspective. Linguistic Approaches to Bilingualism, 3(1): 26-47. https://doi.org/10.1075/lab.3.1.02haz

[8] Sooriyapala, D.K.C.P., Morawaka, M.D.S., Jayasinghe, H.A.P.A., and Fernando, S.G.S. (2016). "Alpha Champ" kids collaborative English learning application. Imperial Journal of Interdisciplinary Research, 2(12): 63-67.

[9] Vogt, P., De Haas, M., De Jong, C., Baxter, P., and Krahmer, E. (2017). Child-robot interactions for second language tutoring to preschool children. Frontiers in Human Neuroscience, 11(73): 1-7. https://doi.org/10.3389/fnhum.2017.00073

[10] Sadig, R.B., Cavus, N., and Ibrahim, D. (2019). Mobile application based on CCI standards to help children learn English as a foreign language. Interactive Learning Environments, https://doi.org/10.1080/10494820.2019.1579239

[11] Golonka, E.M., Bowles, A.R., Frank, V.M., Richardson, D.L., and Freynik, S. (2014). Technologies for foreign language learning: a review of technology types and their effectiveness. Computer Assisted Language Learning, 27(1): 70-105. https://doi.org/10.1080/ $\underline{09588221.2012 .700315}$

[12] Kim, K.H., Kabir, E., \& Jahan, S.A. (2016). The use of cell phone and insight into its potential human health impacts. Environmental Monitoring and Assessment, 188(4): 221. https://doi.org/10.1007/s10661-016-5227-1

[13] Telmesani, M., Ahmad, W., and Telmesani, T.M. (2017). The impact of technology on minors: a survey-based study. Australasian Journal of Business, Social Science and Information Technology, 3(2): 78-90.

[14] Sarwar, M., and Soomro, T. R. (2013). Impact of smartphone's on society. European Journal of Scientific Research, 98(2): 216-226.

[15] Gottschalk, F. (2019). Impacts of technology use on children: exploring literature on the brain, cognition and well-being. OECD Education Working Paper No. 195. Retrieved July 21, 2019 from https://doi.org/10.1787/19939019. https://doi.org/10.1787/8296464e-en

[16] Singh, D., and Tilak, G. (2019). Effect of Technology Devices on Health of Youth in Pune City. Universal Review, 10: 23-35.

[17] Patel, D. (2017). Will technology ruin your children's development? Retrieved May 14, 2019 from https://medium.com/thrive-global/will-technology-ruin-your-childrensdevelopment-663351c76974

[18] Bartikowski, B., Laroche, M., Jamal, A., \& Yang, Z. (2018). The type-of-internet-access digital divide and the well-being of ethnic minority and majority consumers: A multicountry investigation. Journal of Business Research, 82(2018): 373-380. https://doi.org/10. 1016/j.jbusres.2017.05.033

[19] Healey, A., and Mendelsohn, A. (2019). Selecting appropriate toys for young children in the digital era. Pediatrics, 143(1): 1-10. https://doi.org/10.1542/peds.2018-3348

[20] Plowman, L., and Stephen, C. (2005). Children, play, and computers in pre-school education. British Journal of Educational Technology, 36(2): 145-157. https://doi.org/10.1111/ j.1467-8535.2005.00449.x 
[21] Hinske, S., Langheinrich, M., and Lampe, M. (2008, February). Towards guidelines for designing augmented toy environments. In Proceedings of the 7th ACM Conference on Designing Interactive Systems (pp. 78-87). ACM. https://doi.org/10.1145/1394445.139 $\underline{4454}$

[22] Yelland, N. (1999). Technology as play. Early Childhood Education Journal, 26(4): 217220.

[23] Muis, K.R., Ranellucci, J., Trevors, G., and Duffy, M.C. (2015). The effects of technology mediated immediate feedback on kindergarten students' attitudes, emotions, engagement and learning outcomes during literacy skills development. Learning and Instruction, 38: 113. https://doi.org/10.1016/j.learninstruc.2015.02.001

[24] Kekuluthotuwage, P., and Fernando, P. (2017). HomeSchool: an interactive educational tool for child education. In Proceedings of the Information Technology Conference (NITC), (pp. 34-39). IEEE. https://doi.org/10.1109/nitc.2017.8285652

[25] Noor, N.M.M., Mohemad, R., Mamat, N.F.A., FatihahYahya, W.F., Rifin, M.A.S. Hassan, M. N., and Hamzah, M.P. (2017). Teaching and learning module on learning disabilities (LD) using RFID technology, International Journal of Learning and Teaching, 3(4): 251258. https://doi.org/10.18178/ijlt.3.4.251-258

[26] Jeong, H., Saakes, D.P., \& Lee, U. (2015). I-Eng: an interactive toy for second language learning. In Adjunct Proceedings of the International Joint Conference on Pervasive and the Ubiquitous Computing International Symposium on Wearable Computers (pp. 305308). ACM. https://doi.org/10.1145/2800835.2800857

[27] Kubicki, S., Wolff, M., Lepreux, S., and Kolski, C. (2015). RFID interactive tabletop application with tangible objects: exploratory study to observe young children's behaviors. Personal and Ubiquitous Computing, 19(8): 1259-1274. https://doi.org/10.1007/s00779$\underline{015-0891-7}$

[28] Yilmaz, R.M. (2016). Educational magic toys developed with augmented reality technology for early childhood education. Computers in Human Behavior, 54: 240-248. https://doi. org/10.1016/j.chb.2015.07.040

[29] Güngör, B. (2018). The effect of the integration of talking toys on preschoolers' vocabulary learning in English. Erken Çocukluk Çalışmaları Dergisi, 2(2): 180-193. https://doi. org/10.24130/eccd-jecs.196720182255

[30] Pan, L. (2011). English language ideologies in the Chinese foreign language education policies: A worldsystem perspective. Language Policy, 10: 245-263. https://doi.org/10.1007/ s10993-011-9205-8

[31] Bataineh, A.M. (2014). The effect of using computer-mediated communication on English language learners' socio-cultural competence. International Journal of Interactive Mobile Technologies, 8(3): 44-55. https://doi.org/10.3991/ijim.v8i3.3910

[32] Magal-Royo, T., and Garcia-Laborda, J. (2018). Standardization of design interfaces applied to language test on-line through ubiquitous devices. International Journal of Interactive Mobile Technologies, 12(4): 21-31. https://doi.org/10.3991/ijim.v12i4.9197

[33] Suryasa, I. W., Prayoga, I., and Werdistira, I. (2017). An analysis of students' motivation toward English learning as second language among students in Pritchard English academy (PEACE). International Journal of Social Sciences and Humanities, 1(2): 43-50. https:// doi.org/10.29332/ijssh.v1n2.36

[34] San, P.H. and Abdullah, A.C. (2014). Oral vocabulary as a predictor of English proficiency among Malaysian Chinese preschool children. The Southeast Asian Journal of English Language Studies, 20(1): 143-156. https://doi.org/10.17576/31-2014-2001-11 
[35] Sharma, A., and Solanki, K. (2019). English language in India: role and significance in administrative system and educational development. International Journal of English Language, Literature in Humanities, 7(6): 78-87.

[36] Klemenovic, J. (2014). How do today's children play and with which toys? Croatian Journal of Education, 16(1): 181-200.

[37] Johnson, J. E., and Christie, J. F. (2009). Play and digital media, computers in the schools: interdisciplinary journal of practice. Theory, and Applied Research, 26(4): 284-289. https://doi.org/10.1080/07380560903360202

[38] Srivastava, P., and Noval, S. (2019). Evolving Approaches and Developments used in teaching ESL and EFL. International Journal of English Language, Literature in Humanities, 7(6): 1093-1100.

[39] Chu, Y.W. (2014). Teachers' beliefs in teaching English for kids at a kindergarten: a case study of students from the department of applied English. English Language Teaching, 7(10): 100-112. https://doi.org/10.5539/elt.v7n10p100

[40] Barnett, L.A. (2013). Children's perceptions of their play: scale development and validation. Child Development Research, 2013, Article ID 284741. Retrieved July, 21, 2019 from http://dx.doi.org/10.1155/2013/284741. https://doi.org/10.1155/2013/284741

[41] Nacher, V., Garcia-Sanjuan, F., and Jaen, J. (2016). Interactive technologies for preschool game-based instruction: experiences and future challenges. Entertainment Computing, 17: 19-29. https://doi.org/10.1016/j.entcom.2016.07.001

[42] Greener, S. (2014). Smart toys and sophisticated learning tools. Interactive Learning Environments, 22(5): 549-550. https://doi.org/10.1080/10494820.2014.963939

[43] Kenny, R., and McDaniel, R. (2011). The role teachers' expectations and value assessments of video games play in their adopting and integrating them into their classrooms. British Journal of Educational Technology, 42(2): 197-213. https://doi.org/10.1111/j.14678535.2009.01007.x

[44] Creswell, J.W., and Clark, D.V.L.P. (2006). Designing and conducting mixed Methods research (pp. 296). USA: Sage Publications, Inc.

[45] Fraenkel, R.J. and Wallen, N.E. (2011). How to design and evaluate research in education (8th ed.). New York: McGraw-Hill.

[46] Avci, N. (2017). How is a research that children want? Hearing the children's voices during the research process! New Trends and Issues Proceedings on Humanities and Social Sciences, 4(6): 60-69. https://doi.org/10.18844/prosoc.v4i6.2914

[47] Cavus, N., and Ibrahim, D. (2009). M-learning: an experiment in using SMS to support learning new English language words. British Journal of Educational Technology, 40(1): 78-91. https://doi.org/10.1111/j.1467-8535.2007.00801.x

[48] Sipahi, B., Yurtkoru, E. S., and Çinko, M. (2010). Sosyal Bilimlerde SPSS'le Veri Analizi. Istanbul: Beta Yayınları.

[49] West, J., and West, J. (2006). Sunrise-1 Student's Book. Egypt: MacMillan Publications Limited. Retrieved July 21, 2019 from http://www.sunrisekurdistan.com/wpcontent/ uploads/2011/03/Sunrise-SB1-read-only.pdf. https://doi.org/10.18411/a-2017-023

[50] Wang, W., and Li, F. (2020) Preschool Children's Product Design Based on Heart Flow Theory. In R. Goonetilleke, and W. Karwowski (Eds.), Advances in Physical Ergonomics and Human Factors (Advances in Intelligent Systems and Computing, vol 967). Cham: Springer. https://doi.org/10.1007/978-3-030-20142-5_5

[51] Alqahtani, M. (2015). The importance of vocabulary in language learning and how to be taught. International Journal of Teaching and Education, 3(3), 21-34. https://doi.org/10. $\underline{20472 / \text { te.2015.3.3.002 }}$ 
Paper-Developing Electronic Device to Teach English as a Foreign Language: Educational Toy...

\section{Authors}

Abdo Sulaiman Abdi is member of the Duhok Polytechnic University, Duhok, KRG, Iraq. His interests are technology, English teaching, children, and technologybased learning environment. Address for correspondence: abdo.abdi@dpu.edu.krd

Nadire Cavus is a lecturer at the Department of Computer Information Systems, Near East University, Cyprus. Her interests are English teaching, technology, virtual learning environments, and distant learning. Email: nadire.cavus@neu.edu.tr

Article submitted 2019-09-24. Resubmitted 2019-10-27. Final acceptance 2019-10-27. Final version published as submitted by the authors. 